\title{
Globalisation Impact on Indian Banking Services
}

\author{
Dr Jai Prakash Tripathi ${ }^{1}$, Mr. Farid Reshtya ${ }^{2}$ \\ ${ }^{1}$ Dean, MBA, Sri Satya Sai University of Technology \& Medical Sciences, Sehore \\ ${ }^{2}$ Sri Satya Sai University of Technology \& Medical Sciences, Sehore
}

\begin{abstract}
In India the Banking situation has experienced enormous changes and they are confronting intense rivalry in the post progression condition. The Banking today is something creative which couldn't be envisioned before two decades. In the aggressive administration the Information Technology is the foundation of the saving money exercises. Data is at the heart of today's business, and the all-unavoidable effect of Information Technology in saddling, grouping and preparing enormous volumes of data is conclusive. It is imperative to note that by and by right around 98 for each penny of the branches of open segment banks are completely mechanized, and inside which very nearly 90 percent of the branches are on center managing an account stage. In this specific circumstance, the creator tries to draw out the development of IT empowered administrations of Indian managing an account industry by taking computerization of banks, reach of ATMs region insightful, bank astute and area shrewd and the utilization of Debit and Credit Cards. The creator connected the measurable instruments like Trend investigation, rate examination, relationship investigation, coefficient of assurance and exponential development rates close to the utilization of diagrams and tables. The conclusion got from the paper is that there is an enormous development of mechanical applications in the keeping money part with the exception of in the use of charge cards.
\end{abstract}

Keywords: ATMs, Banking, Computerization, Credit Cards, Debit Cards, Technology, Trend.

\section{Presentation}

The idea of Globalization construes that the globe is a solitary unit which works as one with regards to basic leadership. At the end of the day, Globalization infers the free development of merchandise, administrations and capital all through the world. Globalization includes the opening up of national economies to worldwide markets. This normally and at the same time brings about the synchronous decrease in the part of the State to shape national approaches. Numerous Socialists characterize Globalization as an essentially financial marvel, which includes expanding association and incorporation of national monetary frameworks. This leads thusly to development in worldwide exchange, venture and capital streams. Also, there is a fast increment in cross-fringe social, social and mechanical trades in view of the wonder of globalization.

The humanist characterizes globalization as a decoupling of space and time. With the approach of quick interchanges, learning, exchange and culture can be shared the world over at the same time. This will at last outcome in an expansion in worldwide exchange, speculation and capital streams.

Then again, a few pundits characterize Globalization as "the overall drive towards a globalized monetary framework, ruled by supranational corporate exchange and keeping money organizations that are not responsible to the vote based procedures or national governments. Because of Globalization, exceptionally imperative foundations like the country, state, family, work, administrations, exchange, recreation, culture, learning and so forth are evolving. Subsequently, ways of life of individuals all through the world are likewise changing, making the world a solitary unit with regards to basic leadership.

\section{Effect of Globalization on Banking Services In India}

The center and late 90s saw extraordinary developments in budgetary changes, rebuilding, union globalization and so forth. These were joined by a quick transformation in correspondence advances. Besides, a noteworthy improvement was the advancement of the ""meeting"" of PC and correspondence advances, for example, the Internet, versatile/mobile phones and so on. The landing of outside and private manages an account with their prevalent, refined innovation based administrations constrained Indian Banks likewise to take after the same by going in for the most recent advances in order to meet the danger of rivalry and hold their client base. This likewise got progressive items and administrations which have been organized by the Indian Software Industry.

Programming Packages for Banking Applications in India had their beginnings in the mid 80"s. This move was prodded on by RBI and the Rangarajan Committee Report which chose to automate the Indian Banking branches in a constrained way. This move was gone for advancing rivalry and permits a simple appraisal of relative seller abilities. Bit by bit, even the individuals who contradicted computerization in government and banks changed their viewpoint and inside a couple of years our nation turned into a superpower in Information innovation. The mid 90s saw a fall in equipment costs and the appearance of shabby and modest 
yet powerful PCs and servers. Banks went in for what was called Total Branch Automation (TBA) Packages. We are currently right when we have acknowledged the utilization of PCs in each circle of our action today.

\section{Classifications of Packages}

The IT Packages and administrations accessible in India can be comprehensively arranged into the accompanying 6 sorts:

- Stand-alone branch-level bundles;

- Multi-branch arrangements;

- Foreign bundles;

- Packages for specific specialty territories;

- Service Branch/high-volume exchange handling bundles;

- IT Services;

Subsequently, we have a wide range of Banking Software accessible in the market to satisfy the different needs of the managing an account Industry. There are number of programming organizations, which are creating programming for the keeping money industry.

\section{Audit of Literature}

Mahapatra and Mohanty,(2011), expressed that the Indian Public Sector Banks possess the urgent position in the nation's managing an account geology yet its piece of the pie has declined to some degree as of late because of the development of private part and outside banks.

Uppal R K, (2010), the key undertaking of the bank is not exclusively to make and win an ever increasing number of clients additionally to hold them through compelling client benefit. Clients are pulled in through guarantees and are held through fulfillment of desires, needs and needs.

Jain, A. (2007) portrayed that advertiser needs to realize that every single nation is having different promoting condition. Similarly, it must be evident that the worldwide advertiser will undoubtedly hang on the revamping that each promoting condition contrasts from place to put and additionally country to country than that of a similar nation state. It is additionally clear from the review that the worldwide business exchanges must be sound arranged and destinations situated in nature.

Dwivedi, R. (2007) clarified that fund capacities are vital however not as imperative as the showcasing capacities. Contact between the showcasing and fund capacities would be impeding to the smooth improvement and working of any business association. Back targets like esteem boost to shareholders are vital parts of any new system embraced by the association.

Goals:

1. To look at the globalized practices of items and administrations in different bank bunches.

2. To recommend a few systems for the improvement of bank in globalization

In Today:

The whole managing an account division has experienced a rebuilding amid late years subsequently of late advancements. New advancements have added to the opposition. The I-T insurgency has made it conceivable to give simplicity and adaptability in operations to clients accordingly making life less difficult and less demanding.

\section{Effect of Globalization on Banking Services in India}

Data innovation has, indeed, re-imagined the part and structure of keeping money in India. Further, because of presentation to worldwide patterns after Information blast drove by Internet, clients - both Individuals and Corporates - are currently requesting better administrations with more items from their banks. The money related market has transformed into a purchaser's market. Banks are additionally adapting and adjusting to time and are attempting to end up distinctly one-stop budgetary general stores. The market center is moving from mass keeping money items to class managing an account with the presentation of significant worth included and tweaked items.

Open Sector Banks like SBI have likewise begun concentrating on this region. SBI arrangements to open 100 new branches called Personal Banking Branches (PBB) this year. The PBBs will likewise market SBI's whole range of advance items: e.g. lodging advances, auto advances, individual credits, shopper tough advances, instruction advances, advances against shares and financing against gold.

Redone keeping money items, for example, Investment Advisory Services; photograph charge cards; money Management administrations; Investment items and Tax Advisory administrations have as of now been presented by a couple of remote and private segment banks. A couple banks have gone into market shared store 
plans. In the long run, the Banks plan to market securities and debentures, when permitted. Protection hawking by Banks will be a reality soon. The current Credit Policy of RBI reported on April 27, 2000 has additionally encouraged the passage of banks in this division. Banks additionally offer counseling administrations named as 'private managing an account' to "high relationship esteem" customers.

The bank without bounds must be basically a showcasing association that likewise offers saving money items. New dispersion channels are being utilized; more and more banks are presenting administrations like dispensing and overhauling of buyer advances, Credit card business. Coordinate Selling Agents (DSAs) of different Banks go out and offer their items. They make house calls to get the application shape filled in appropriately and furthermore take your travel permit estimated photograph. Home saving money has as of now get to be distinctly normal. Presently, you can arrange a draft or money via telephone or web and have it conveyed home. ICICI was the first among the new private banks to dispatch its net managing an account benefit, called Infinity. It permits the client to get to record data over a protected line, ask for Check books and stop installment, and considerably exchange finances between ICICI Bank accounts. Citibank has been putting forth net saving money to clients.

Items like Visas, platinum cards, flexi stores, ATM cards, individual advances including purchaser credits, lodging advances and vehicle advances have been presented by various banks.

\section{Points of interest For Corporates}

Corporates are likewise getting benefits from the expanded assortment of items and rivalry among the banks. Endorsements of store, Commercial papers, Non-convertible Debentures (NCDs) that can be exchanged the auxiliary market are picking up ubiquity. As of late, market has likewise observed real improvements in treasury counseling administrations. With the presentation of Rupee coasting rates for stores and in addition propels, items like financing cost swaps and forward rate assentions for remote trade, hazard administration items like forward contracts, choice contracts and cash trade are offered by practically every approved merchant bank in the market. This rundown of administrations is as yet developing.

\section{Conclusion}

Shockingly, a few concerns identified with the saving money area still remain. The boss among these is the matter of proprietorship and control. Sooner rather than later, India will be compelled to apply the standards of created nations to the Banking Industry. Thus, numerous Indian banks (counting a portion of the greatest) will demonstrate extremely poor return proportions and many banks will go bankrupt. Along these lines, it gets to be distinctly basic that the Banking Industry ought to streamline itself and turn out to be more good with worldwide standards in the fields of operation and administrations.

Indian Banks have gigantic budgetary assets available to them. We began with total stores of around 5000 Crores in the Sixties which expanded to 10 Lakh Crores this thousand years. This means a 200-hundredcrease development in three decades. A noteworthy apparatus which we have available to us is our insight capital-something which is in effect terribly underutilized at present. This is a greatly profitable kind of capital. In managing an account we are shy of immaterial resources. Our insight capital is very vital to the accomplishment of saving money in India. This we can't gather from outside; neither would we be able to go in for an open issue to prepare immaterial resources. Along these lines saving money representatives need to grasp the requirement for higher learning and better information. Saving money in India has massive potential given the populace figures in our nation. With a little exertion, watchful arranging and convenient enactment this industry can be carried comparable to the best banks on the planet. Banks are conveying innovation for executing separated procedure and hazard administration systems. Expanding IT interests in these territories will likewise bring a proactive and straightforward observing and consistence condition inside Banks.

\section{References}

[1]. Egware, L. E. (2009). "Institutional Agents of Globalization". CBN Economic and Financial Review, 36(4), 352

[2]. Elyasiani, E. and Mehdian, S. (1995). "The Comparative Efficiency Performance of Small and Large U.S. Commercial Banks in the Pre and Post Deregulation Eras". Applied Economics, 27, 1069-79.

[3]. Ezike E. (2009). International Business Finance and Management. Lagos: Concept Publications Limited.

[4]. Ferrier, G.D. and Lovell, C.A.K. (1990). "Measuring Cost Efficiency in Banking: Econometric and Linear Programming Evidence". Journal of Econometrics, 46, 229-245.

[5]. Somoye, R.O.C. (2008). "The Performances of Commercial Banks in Post- Consolidation Period in Nigeria: An Empirical Review." European Journal of Economics, Finance and Administrative Sciences, ISSN 1450-2275, Issue 14

[6]. Chang, T.Y. (2003), Dynamics of banking technology adoption: an application to Internet banking. Department of Economics, Coventry: University of Warwick.

[7]. Eriksson, K., Kerem, K., Nilsson, D. (2005) Customer acceptance of internet banking in Estonia. International Journal of Bank Marketing, 23(2): 200-216.

[8]. Chakrabarty K C (2010) New Paradigms in IT Security in Indian Banks, Inaugural Address at DSCI Conference on: Security Framework in Indian Banks?, Mumbai. 
[9]. Ruddar Datt and Sundharam K.P.M (2009), Indian Economy Sultan and Chand, New Delhi 11. www.rbi.org 